\title{
DFT Provides Insight into the Additive-Free Conversion of Aqueous Methanol to Dihydrogen Catalyzed by [Ru(trop 2 dad)]: Importance of the (Electronic) Flexibility of the Diazadiene Moiety
}

\author{
Vivek Sinha, ${ }^{\dagger}$ Monica Trincado, ${ }^{*}$ Hansjörg Grützmacher, ${ }^{*}{ }^{*}$ and Bas de Bruin* ${ }^{\dagger}$ (৫) \\ ${ }^{\dagger}$ Homogeneous, Supramolecular and Bio-inspired Catalysis Group (HomKat), van 't Hoff Institute for Molecular Sciences (HIMS), \\ Universiteit van Amsterdam, Amsterdam 1012 WX, The Netherlands \\ ${ }^{\ddagger}$ Laboratorium für Anorganische Chemie, ETH, Zürich 8092, Switzerland
}

Supporting Information

\begin{abstract}
The mechanism for complete dehydrogenation of aqueous methanol to $\mathrm{CO}_{2}$ and three equivalents of $\mathrm{H}_{2}$ catalyzed by $\left[\mathrm{Ru}\left(\operatorname{trop}_{2} \mathrm{dad}\right)\right]$ was investigated with DFT (trop $\mathrm{dad}_{2}=1$,4-bis $(5 H$-dibenzo[ $a, d]$ cyclohepten-5-yl)-1,4-diazabuta-1,3-diene). To date, this is the only catalyst that promotes the acceptorless dehydrogenation of aqueous methanol in homogeneous phase under mild conditions without the addition of an additive (base, acid, or a secondary catalyst). A detailed understanding of the mechanism of this transformation may therefore be of significant importance for the conversion of liquid organic fuels. Previous computational studies using simplified models of the catalyst suggested entirely ligandcentered reaction pathways with rather high-energy barriers for complete dehydrogenation of aqueous methanol. These are, however, not consistent with the experimental data. In the present paper, we reveal a different reaction mechanism for aqueous methanol dehydrogen-

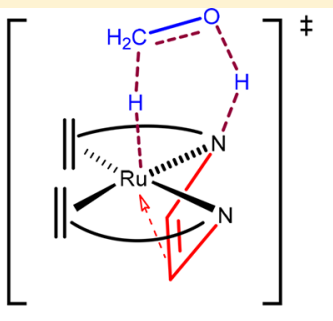

Metal-Ligand Cooperativity ation that involves metal-ligand cooperativity involving the diazadiene (dad) ligand and has substantially lower barriers, in good agreement with the experimental data. The dad moiety of the ligand actively participates in the alcohol activation mechanism. In the first step of the reaction, the dad ligand rearranges from a $\sigma$ - to a $\pi$-bound coordination mode. This adjusts the electronic structure of both the metal and the ligand, leading to an enhanced Brønsted basicity of the nitrogen centers and higher Lewis acidity of the ruthenium center. As a result, concerted proton-hydride transfer to/from metal-hydride and $\mathrm{N}$-protonated dad-ligand moieties becomes possible, leading to low-barrier metal-ligand cooperative elementary steps for alcohol activation and $\mathrm{H}_{2}$ elimination.
\end{abstract}

\section{INTRODUCTION}

Hydrogen is an attractive energy carrier for the clean and efficient generation of electricity using fuel cell technologies. In spite of the advantages that fuel cells entail, hydrogen storage is one of the main limitations to enable a hydrogen-based energy system. Consequently, the reversible chemical fixation of hydrogen in a carrier molecule, especially a stable liquid compound, may offer a practical alternative for hydrogen handling. Methanol is a particular promising liquid organic fuel (LOF) with a gravimetric hydrogen content of $12.6 \mathrm{wt} \%$. The complete dehydrogenation of a methanol/water mixture (hydrogen content $12.4 \mathrm{wt} \%)$ gives rise to the release of $\mathrm{CO}_{2}$ and three equivalents of $\mathrm{H}_{2}$. Given an environmentally benign and cost-efficient source of hydrogen coupled with an efficient recycling process of $\mathrm{CO}_{2}$, methanol might become a real alternative for sustainable hydrogen storage. In this scenario the system $\mathrm{CH}_{3} \mathrm{OH} / \mathrm{CO}_{2}$ takes the role of recyclable hydrogen carrier. ${ }^{1}$ The overall process would in effect mimic the natural carbon cycle. ${ }^{2}$ However, the possibility of reversible hydrogen storage in methanol is still not broadly commercially developed. This is mainly due to the limitations related to the highly energetically costly full dehydrogenation and the reverse hydrogenation processes. Methanol reforming in the presence of heterogeneous catalysts typically requires high temperatures $\left(>200{ }^{\circ} \mathrm{C}\right)$ and high pressures $(25-50 \mathrm{bar}) .^{3}$ The main problems at these temperatures are the competing methanol decarbonylation and reverse water gas shift reaction (RWGS), leading to $\mathrm{CO}$ as an undesired product. Recent advances in the reforming of methanol under mild conditions based on homogeneous catalyzed processes have raised the expectations on this fuel. With the exception of the initial work of ColeHamilton on methanol reforming catalyzed by a rhodium bipyridine complex, ${ }^{4}$ only recently were two molecular $\mathrm{Ru}$ complexes found that act as homogeneous catalysts ${ }^{5,6}$ allowing the conversion of aqueous methanol below $100{ }^{\circ} \mathrm{C}$ and at atmospheric pressure. In both catalytic systems chemically "noninnocent" ligands bind to the metal center. The catalysis is efficient and highly selective, and no CO was detected. Several theoretical studies have been reported exploring possible mechanisms of these reactions. Subsequent experimental studies used other ruthenium, ${ }^{7,8}$ iridium, ${ }^{9}$ or rhodium ${ }^{10}$ complexes. More recently, the first catalytic reactions with first-row metal complexes $\left(\mathrm{Fe}^{11}\right.$ and $\mathrm{Mn}^{12}$ ) were reported. But the development of efficient

Received: August 23, 2018

Published: September 14, 2018 

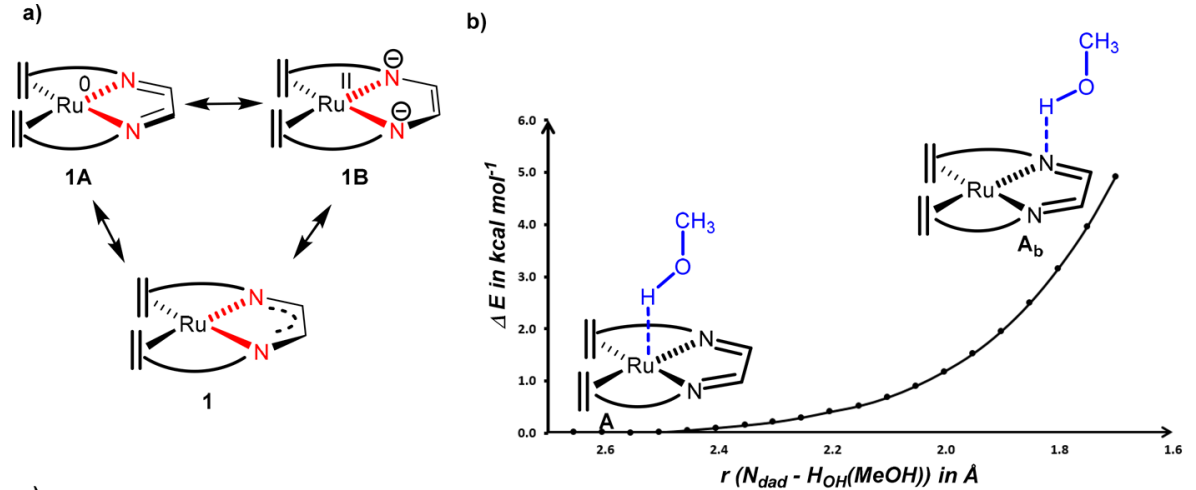

c)

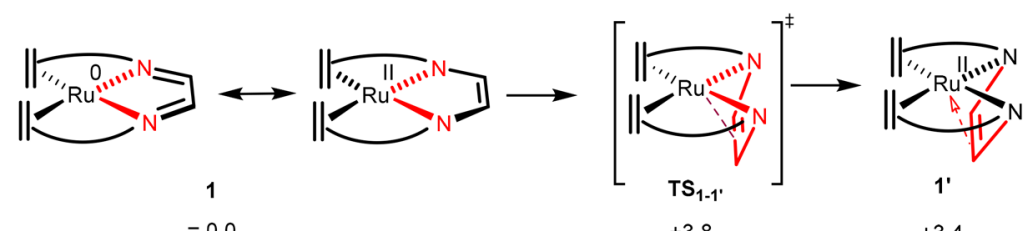

d)
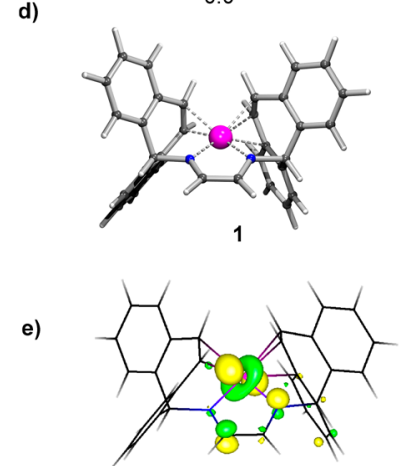

HOMO
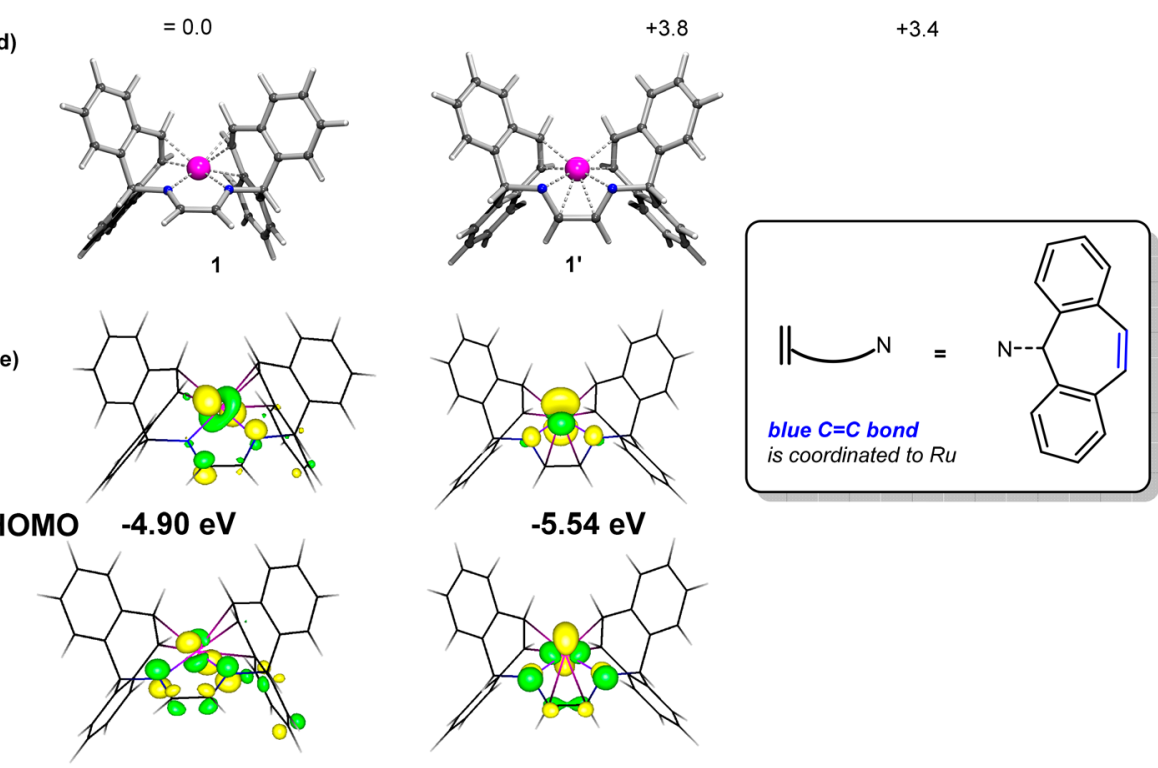

LUMO $-2.43 \mathrm{eV}$

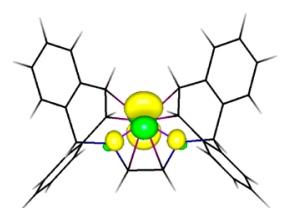

$-5.54 \mathrm{eV}$

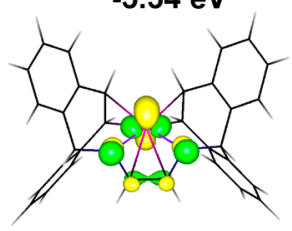

$-2.27 \mathrm{eV}$

Figure 1. (a) The electronic structure of complex 1 can be described with two contributing resonance structures: $\mathbf{1 A}$, with ruthenium in oxidation state 0 coordinated to a neutral dad moiety, and 1B, with ruthenium in oxidation state +II coordinated to a dianionic dad moiety. (b) Potential energy surface (PES) scan to drive the $\mathrm{H}_{\mathrm{OH}}$ in methanol $\left(\mathrm{H}_{\mathrm{OH}}(\mathrm{MeOH})\right.$ ) to one of the $\mathrm{N}_{\mathrm{dad}}$ atoms. In complex $\mathbf{A}$, methanol prefers to bind via the $\mathrm{OH}$ group to the metal center, indicating a larger contribution of resonance structure $\mathbf{1 A}$ to the ground state of complex $\mathbf{1}$. The vertical axis represents the relative SCF energy $(\Delta E)$ (BP86/def2-SVP), while the horizontal axis represents the distance between the $\mathrm{N}_{\mathrm{dad}}$ atom and MeOH hydroxyl proton. (c) Transformation of complex 1 to the $\pi$-coordinated complex $\mathbf{1}^{\prime}$. (d) 3D structure plots of complexes 1 and $\mathbf{1}^{\prime}$. (e) Highest occupied molecular orbital (HOMO) and lowest unoccupied molecular orbital (LUMO) of complex $\mathbf{1}$ (left) and complex $\mathbf{1}^{\prime}$ along with their respective energy (right) (contour plots drawn at $0.08 \mathrm{au}$ ).

catalysts for the additive-free dehydrogenation of methanol aqueous solutions under mild conditions remains a major challenge. To date, the only system that promotes the dehydrogenation of methanol in the absence of any additives (base, acid, or a secondary catalyst) is the diazadiene ruthenium complex $\left[\mathrm{Ru}(\text { trop })_{2} \mathrm{dad}\right]$ (trop $\mathrm{dad}_{2}=1,4$-bis $(5 H$-dibenzo $[a, d]$ cyclohepten-5-yl)-1,4-diazabuta-1,3-diene) (see Figure 1d for a plot of the structure). ${ }^{6}$ If one does not want to rely on serendipity, a detailed understanding of the elementary steps involved in the catalytic reaction is necessary for the development of catalysts with improved efficiency. In this study, we present a plausible novel mechanism on the basis of DFT calculations, considering elementary steps based on metal-ligand cooperativity that were previously not considered. This allows us to propose a new mechanism for the dehydrogenation of a methanol-water mixture to $\mathrm{CO}_{2}$ and hydrogen catalyzed by the $\left[\mathrm{Ru}\left(\right.\right.$ trop $\left.\left._{2} \mathrm{dad}\right)\right]$ system, which is based on metal-ligand cooperativity. The dad ligand moiety plays a crucial and active role in catalysis, which first rearranges from a $\sigma$ - to a $\pi$-bound coordination mode to allow essential catalytic elementary steps.

Dehydrogenation of methanol-water mixtures by the $\left[\mathrm{Ru}(\text { trop })_{2} \mathrm{dad}\right]$ catalyst proceeds via four separate steps (Scheme 1a): (a) methanol is dehydrogenated (oxidized) to formaldehyde under release of the first equivalent of $\mathrm{H}_{2}$; (b) formaldehyde undergoes hydration to form methanediol; (c) methanediol is dehydrogenated to formic acid and a 
Scheme 1. (a) Four stages (1-4) of the Stepwise Dehydrogenation of a Methanol-Water Mixture to $\mathrm{H}_{2}$ and $\mathrm{CO}_{2}$; (b) Proposed Metal-Ligand Cooperative Pathway for Dehydrogenation of Methanol-Water Mixtures by Grützmacher and Co-workers; (c) Anionic Pathway Proposed by $\mathrm{Li}$ and Hall via Complex $\mathbf{1 H}^{-}$Containing a Frustrated Lewis Acid Base Pair ${ }^{a}$

a)

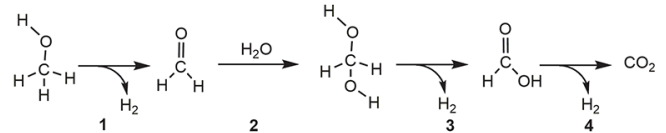

b) Grützmacher and co-workers

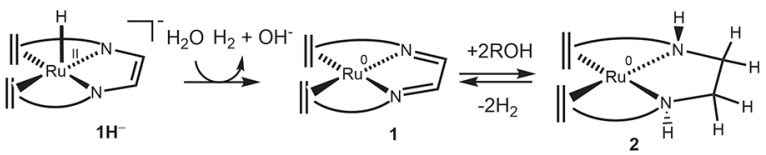

c) Li \& Hall

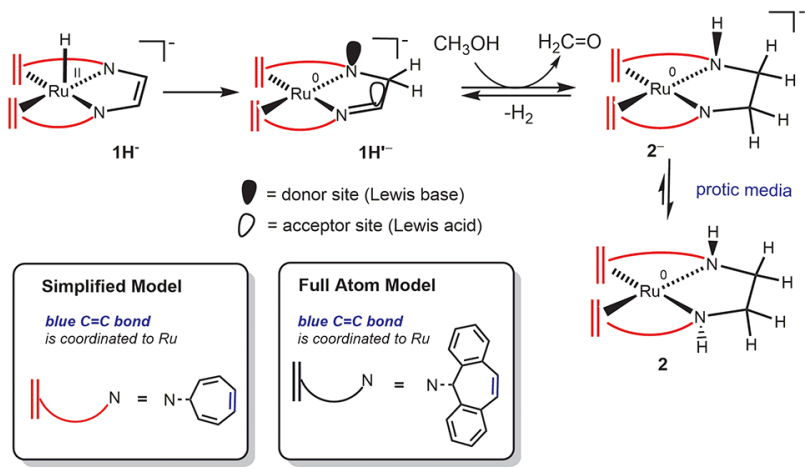

${ }^{a}$ Only methanol is shown as substrate molecule but also methanediol $\left(\mathrm{H}_{2} \mathrm{C}(\mathrm{OH})_{2}\right)$ or formic acid $(\mathrm{HCOOH})$ can be converted.

second equivalent of $\mathrm{H}_{2}$; (d) formic acid is dehydrogenated to release $\mathrm{CO}_{2}$ and the third equivalent of $\mathrm{H}_{2}$. The active $\left[\mathrm{Ru}\left(\right.\right.$ trop $\left.\left._{2} \mathrm{dad}\right)\right]$ catalyst is produced by protonation of the anionic hydride precursor complex $\left[\mathrm{RuH}\left(\text { trop }_{2} \mathrm{dad}\right)\right]^{-}\left(\mathbf{1 H}^{-}\right)$ (Scheme 1b). Compared to most of the other first/secondrow transition metal complexes that are known in the literature ${ }^{5,7,8,9 c, 11,12}$ for aqueous methanol reforming, the active catalyst complex $\left[\mathrm{Ru}\left(\right.\right.$ trop $\left.\left._{2} \mathrm{dad}\right)\right]$ (1) (Figure 1d) does not contain phosphorus donors in the ligand. ${ }^{13}$ Complex $\mathbf{1 H}^{-}$ rather features relatively soft olefinic binding sites, which act as $\pi$-donor and acceptor groups coordinated to the metal from the rigid 1,4-bis (5H-dibenzo $[a, d]$ cyclohepten-5-yl) (abbreviated as trop) ligand. Opposite the $\mathrm{C}=\mathrm{C}_{\text {trop }}$ units are hard $\mathrm{N}$-donor atoms provided by the dad (1,4-diazabuta-1,3-diene) moiety.

In the original experimental paper reported by Grützmacher, Trincado, and co-workers, the dad moiety of the ligand was already proposed to play an important role in the mechanism, but was considered to act as a unit that reversibly stores hydrogen. The $\left[\mathrm{Ru}\left(\right.\right.$ trop $\left.\left._{2} \mathrm{dad}\right)\right]$ complex is best described by two resonance structures with either a $\mathrm{Ru}^{0}$ or a $\mathrm{Ru}^{\mathrm{II}}$ center (vide infra). Complex 1 reacts with methanol, methanediol, or formic acid to form the $\mathrm{Ru}^{0}$ complex 2, which has two equivalents of $\mathrm{H}_{2}$ "stored" in the dad backbone of complex 1 . Both complexes $\mathbf{1}$ and $\mathbf{2}$ were postulated to be intermediates within the same catalytic cycle. Dehydrogenation of complex 2 releases the two equivalents of $\mathrm{H}_{2}$ incorporated in the ligand to regenerate complex $\mathbf{1}$, which closes the catalytic cycle (see Scheme 1b). However, while plausible at the time, these experimental observations can also be interpreted differently. The mere fact that complexes $\mathbf{1}$ and $\mathbf{2}$ are both detectable does not mean that they are necessarily involved in the same catalytic cycle. They could act as independent catalysts, simply being in equilibrium.

In a recent computational study, $\mathrm{Li}$ and Hall primarily focused on a mechanism proposed in the original experimental paper, in which species $\mathbf{1}$ and $\mathbf{2}$ are intermediates in the same catalytic cycle. With density functional theory (DFT) methods, they computed a pathway for the formation of complex $\mathbf{2}$ from $\mathbf{1} \mathbf{H}^{-}$by hydrogen transfer from a substrate molecule (methanol/methanediol/formic acid), followed by a solventor substrate-assisted protonation step (see Scheme 1c). ${ }^{14}$ They found that dehydrogenation of complex 2 proceeds via a very high barrier at a transition state (TS) of $>50 \mathrm{kcal} \mathrm{mol}^{-1}$. For that reason, they proposed an alternative pathway that involves anionic ruthenium complexes ${ }^{15} \mathbf{1 H}^{\prime-}$ and $\mathbf{2}^{-}$(Scheme 1c). In their proposal, the first step involves transfer of the hydride ligand of complex $\mathbf{1 H}^{-}$from $\mathrm{Ru}$ to the dad moiety, generating complex $1 \mathbf{H}^{\prime-}$. The resulting amido and the imine $(\mathrm{N}=\mathrm{C})$ unit in the ligand of complex $\mathbf{1} \mathbf{H}^{\prime-}$ form a Brønsted base and Lewis acid pair, respectively. This frustrated Lewis-acid-base pair acts as the catalytically active site and converts methanol or methanediol in a concerted protonation of the amido moiety and hydride transfer to the imine moiety. This reaction leads to complex $\mathbf{2}^{-}$. In their mechanistic proposal the metal acts as a spectator, while all substrate activation steps occur at the ligand. On the contrary, our recent study of the dehydrogenation of formaldehyde-water mixtures by complex $\mathbf{1} \mathbf{H}^{-}$ revealed an active involvement of the metal center. ${ }^{16}$ A similar metal-centered reactivity can therefore be expected in the steps leading to methanol dehydrogenation. $\mathrm{Li}$ and Hall considered the direct dehydrogenation of complex $\mathbf{2}^{-}$as the hydrogen production step, which was proposed to be the turnoverlimiting step of the catalytic cycle. A high barrier of about $35 \mathrm{kcal} \mathrm{mol}{ }^{-1}$ for the transformation $\mathbf{2}^{-} \rightarrow \mathbf{1 H}^{-}+\mathrm{H}_{2}$ was computed, which is too high and not in agreement with a fast catalytic reaction performed at $363 \mathrm{~K}$.

More recently, Yang and co-workers calculated additional pathways for the dehydrogenation of methanol-water mixtures that likewise involved anionic pathways using $\mathbf{1} \mathbf{H}^{-}$as catalyst. ${ }^{17}$ In both of these studies the activation barriers leading to hydrogen production proved to be very high $\left(>+40 \mathrm{kcal} \mathrm{mol}^{-1}\right){ }^{18}$ None of the previous computational studies took the possibility of metal-ligand cooperativity into account or considered pathways that involve neutral Ru complexes such as complex $\mathbf{1}$. Furthermore, these calculations used simplified models of the catalyst in which the dibenzo[ $[a, d]$ cyclohepten-5-yl (trop) units were replaced by simple cycloheptatrienyl groups. In the present work we show that metal-ligand cooperative pathways calculated for neutral species using a full-atom treatment of the catalyst lead to reaction paths with much lower barriers. Additionally, we show that the use of simplified models of the catalyst leads to unsystematic errors and should be avoided.

\section{COMPUTATIONAL METHODS}

All DFT geometry optimizations were carried out with the Turbomole program ${ }^{19}$ coupled to the PQS Baker optimizer ${ }^{20}$ via the BOpt package. ${ }^{21}$ The BP86 $6^{22,23}$ functional with a Turbomole def2-TZVP basis set ${ }^{24}$ for all atoms was used for optimization of geometries as minima or transition states. The resolution-of-identity (ri) approximation ${ }^{25-27}$ was employed to speed up calculations. To include weak interactions, all calculations include Grimme's 


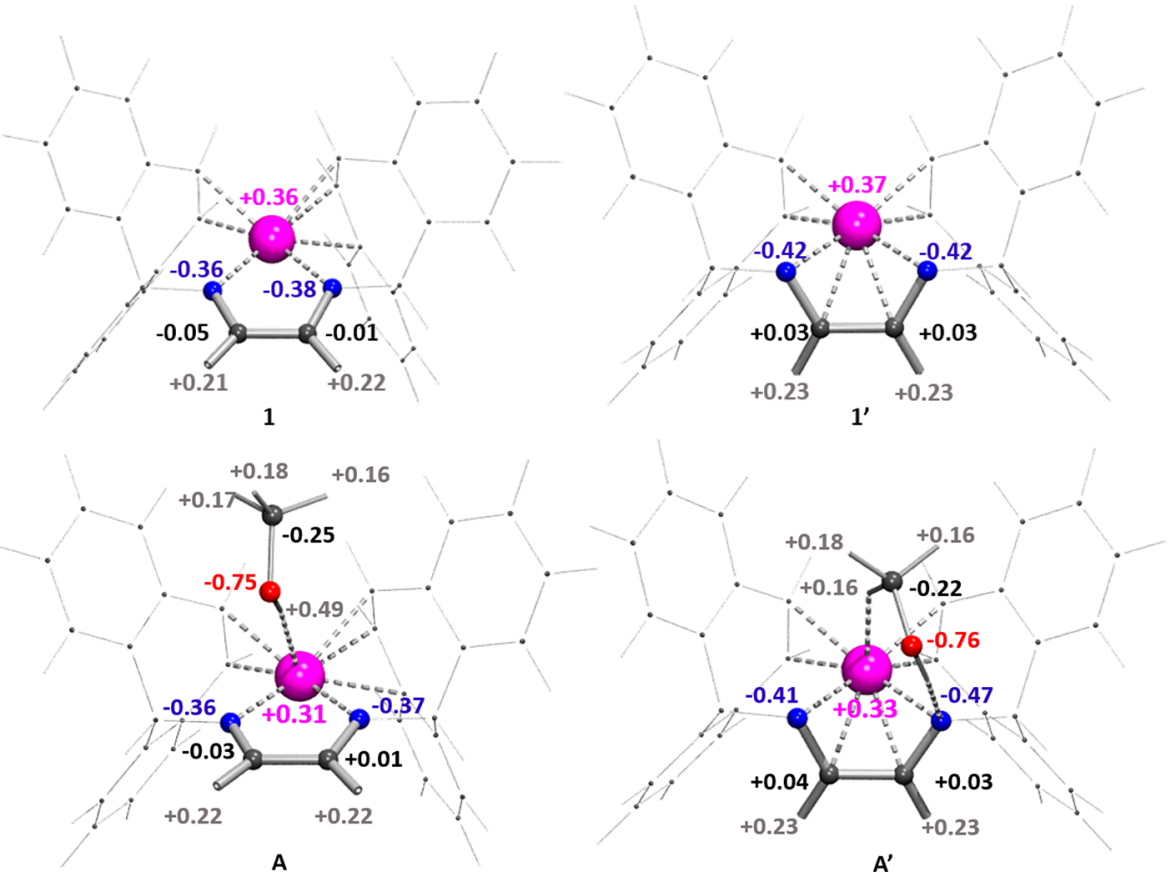

Figure 2. Natural population analysis of complexes $\mathbf{1}$ and $\mathbf{1}^{\prime}$ (top row) and their methanol adducts, complexes $\mathbf{A}$ and $\mathbf{A}^{\prime}$ (bottom row), respectively. The most relevant parts of the complexes are highlighted for clarity (BP86//B3LYP (Water)).

dispersion corrections (D3 version). ${ }^{28}$ Hessian matrix calculations were performed to characterize all minima (no imaginary frequencies) and transition states (one imaginary frequency). IRC calculations were performed to confirm the nature of the transition states. Thermochemical parameters such as the zero-point energy, enthalpy, and Gibbs free energy were calculated using the gas phase Hessian computed at the BP86/def2-TZVP level of theory. Improved (free) energies were obtained with single-point calculations using hybrid exchange functionals (XC). In this paper, the representation "BP86//XC(Solvent)" stands for single-point SCF calculations performed using $\mathrm{XC}$ functional ( $\mathrm{XC}=\mathrm{B} 3 \mathrm{LYP}, \mathrm{M} 06$, etc.) with implicit solvent corrections $(\mathrm{COSMO})^{29}$ using the dielectric constant for "Solvent" (Solvent = water, THF, etc.) on the gas phase geometry optimized using the BP86 functional. Optimized geometries of all stationary states and transition states are supplied in xyz format in the Supporting Information. We also computed the minimum energy reaction path (MERP) of the rate-determining step (methanol to formaldehyde formation) with different XC functionals (PBE0, M06, B3LYP, and BP86) and compared the performance of B3LYP and M06 functionals with respect to the DLPNO-CCSD $(\mathrm{T})$ method. Moreover, we explored the effect of (implicit) solvent phase optimization of intermediates and transition states involved in the MERP using the COSMO model. These results, presented in the Supporting Information, indicate that BP86//B3LYP (Water) provides accurate barriers and the mechanisms obtained with different levels of theory are mutually consistent.

Note that the reactions described in the main text focus on the catalytic reactions of $\left[\mathrm{Ru}\left(\operatorname{trop}_{2}\right.\right.$ dad $\left.)\right]$ complex 1 , but the mechanism of methanol dehydrogenation by $\left[\mathrm{Ru}\left(\right.\right.$ trop $\left.\left._{2} \mathrm{dae}\right)\right]$ complex 2 was also investigated (see Supporting Information for details).

\section{RESULTS AND DISCUSSIONS}

Catalyst Activation and Electronic Structure of Complex 1 . The anionic hydride complex $1 \mathbf{H}^{-}$was reported to react with a slight excess of water or a carboxylic acid to produce the active catalytic neutral complex $\mathbf{1}$ and $\mathrm{H}_{2}{ }^{6,13}$ Complex 1 can be described as a resonance hybrid of two valence isomers, namely, $\mathbf{1 A}$, with $\mathrm{Ru}^{0}$ coordinated to a neutral bis-imine form of the dad moiety, and $\mathbf{1 B}$, which has $\mathrm{Ru}^{\mathrm{II}}$ coordinated to a dianionic bis-amide (Figure 1a)..$^{6,13,16,30}$ The valence isomer $\mathbf{1 B}$ has larger negative charge densities on the $\mathrm{N}_{\mathrm{dad}}$ atoms, which makes them favorable donor sites for hydrogen-bonding interactions. Resonance structure $\mathbf{1 A}$ has neutral $\mathrm{N}_{\mathrm{dad}}$ atoms, which should be very weak hydrogen bond acceptors. DFT calculations show that methanol prefers to interact with complex 1 via metal-proton-type interactions (Figure $1 \mathrm{~b}$ ) and does not tend to form hydrogen bonds with the $\mathrm{N}_{\mathrm{dad}}$ atoms. This clearly points to a rather basic $\mathrm{Ru}$ center, as indicated in the resonance structure $\mathbf{1 A}$ with $\mathrm{Ru}^{0}$, which is likely the main contributor to the electronic structure of complex 1. This is further bolstered by the concave upward curvature of the potential energy surface (PES), which is obtained when the proton on the hydroxyl group of $\mathrm{MeOH}$ is transferred toward one of the $\mathrm{N}_{\mathrm{dad}}$ atoms (Figure $1 \mathrm{~b}$ ). This observation clearly shows that the $\mathrm{N}_{\mathrm{dad}}$ moieties in complex $\mathbf{1}$ are (if any) very poor proton acceptors. ${ }^{31}$ We therefore investigated the possibility that the dad moiety changes its planar coordination mode, in which only the $\mathrm{N}$ centers bind to the metal, to one in which the $\mathrm{C}=\mathrm{C}$ double bond in the dad ligand undergoes $\pi$-coordination to the metal. This transition profoundly changes the electronic structure of the complex, leading to an increased Lewis acidity at the $\mathrm{Ru}$ center and simultaneously enhanced Brønsted basicity of the $\mathrm{N}_{\mathrm{dad}}$ atoms.

None of the previous theoretical studies on this catalytic system considered the effect of $\pi$-coordination of the dad moiety to the metal center. $\pi$-Coordination of dad ligands has been experimentally observed by Vrieze and Van Koten and co-workers in low-valent ruthenium carbonyl complexes more than 30 years ago. ${ }^{32}$ Constrained geometry scan calculations were used to investigate the $\pi$-coordination of the $\mathrm{C}=\mathrm{C}_{\mathrm{dad}}$ bond of the dad backbone to the metal. This is a slightly endergonic process $\left(+3.4 \mathrm{kcal} \mathrm{mol}^{-1}\right)$, which proceeds over a relatively low barrier with $\mathrm{TS}_{1-1^{\prime}}$ at $+3.8 \mathrm{kcal} \mathrm{mol}^{-1}$ (Scheme 1c). Hence, complex $\left[\mathrm{Ru}\left(\kappa-\mathrm{N}, \kappa-\mathrm{N}\right.\right.$-trop $\left.\left.{ }_{2} \mathrm{dad}\right)\right] \mathbf{1}$ (containing a $\sigma$-bound dad moiety) should be in rapid equilibrium with complex $\left[\mathrm{Ru}\left(\pi\right.\right.$-trop $\left.\left.\mathrm{tad}_{2}\right)\right] \mathbf{1}^{\prime}$, which contains a $\pi$-coordinated dad moiety with nonplanar and more basic $\mathrm{N}_{\mathrm{dad}}$ atoms. Notably, 


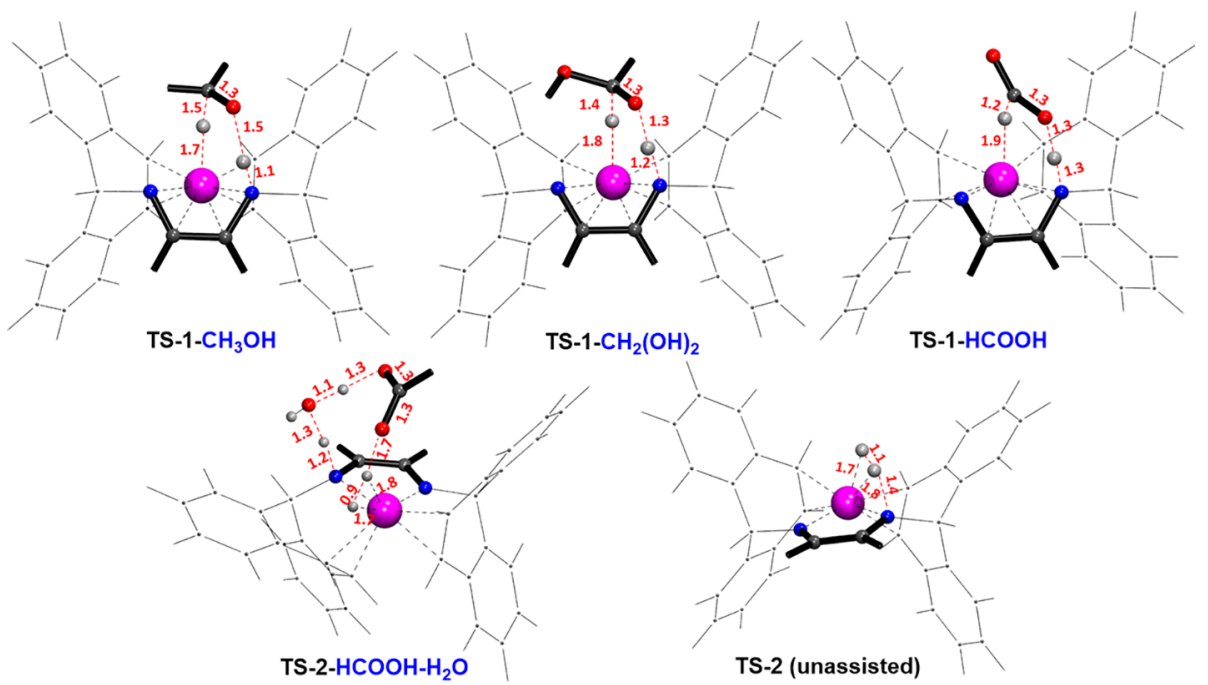

Figure 3. Comparison of relative stabilities (computed Gibbs free energy at $298 \mathrm{~K}$ ) of complexes $\mathbf{1}^{\prime}$ and $\mathbf{1}$ with full-atom and simplified models.

Scheme 2. DFT (BP86//B3LYP (Water))-Calculated Pathway for Dehydrogenation of Methanol to Formaldehyde over Neutral Complex $1^{a}$

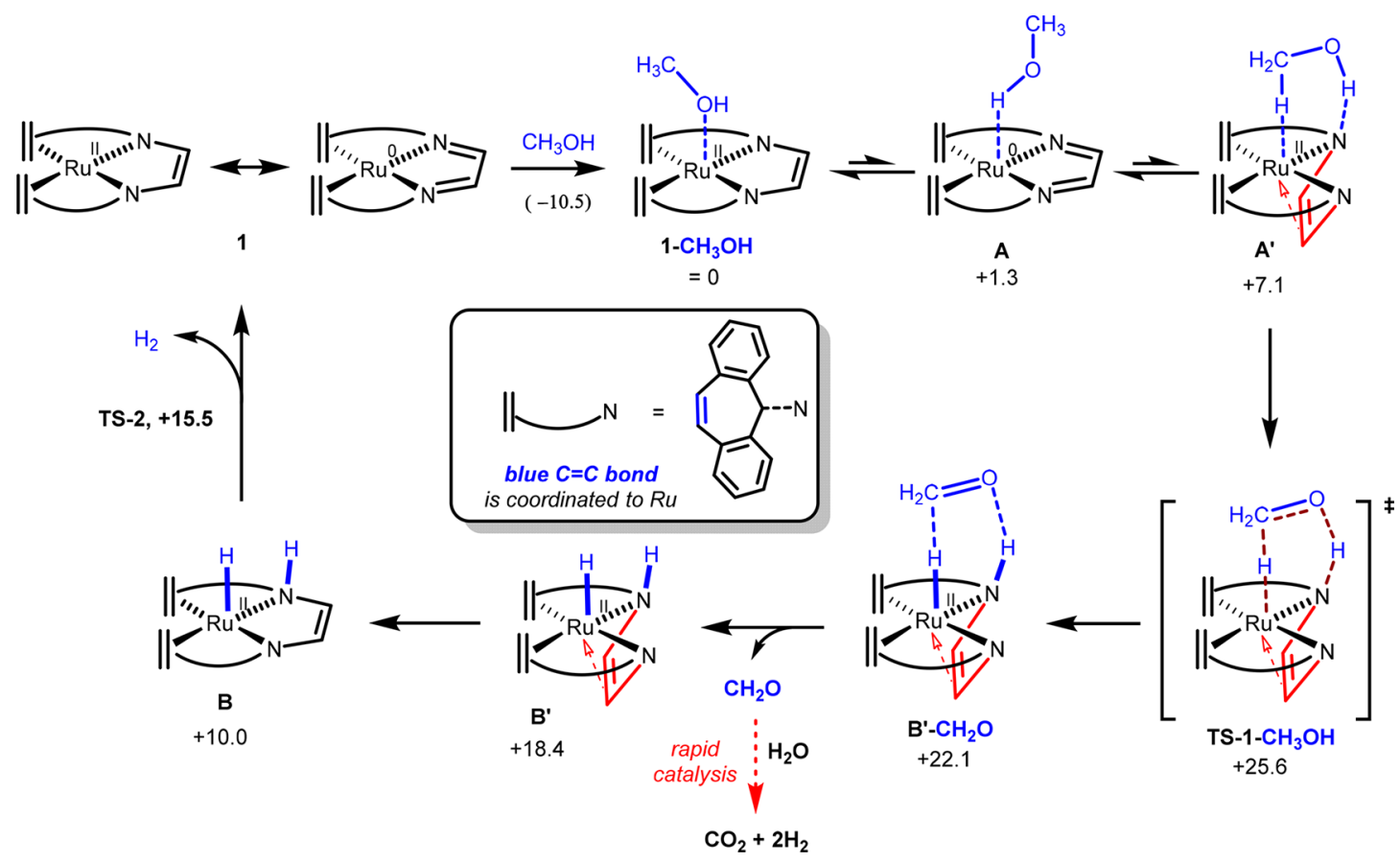

${ }^{a}$ All relative Gibbs free energy values $\left(\Delta G^{\circ}{ }_{298 \mathrm{~K}}\right)$ are reported in $\mathrm{kcal} \mathrm{mol}{ }^{-1}$ relative to $\mathbf{1}-\mathrm{CH}_{3} \mathrm{OH}$. The enthalpy $\left(\Delta H^{\circ}{ }_{298 \mathrm{~K}}\right)$ of the first reaction $\mathbf{1}+\mathrm{CH}_{3} \mathrm{OH}$ is given in parentheses. ${ }^{33-35}$ Transient bonds in transition states are drawn as dashed brown lines.

the investigation of the interaction between $[\mathrm{Ru}(\pi$-trop tad $)] \mathbf{1}^{\prime}$ and methanol using similar constrained geometry scans resulted in a spontaneous rearrangement of the binding mode of the $\mathrm{MeOH}$ molecule (see Supporting Information for details). Starting from adduct $\mathrm{A}$, with the $\mathrm{OH}$ group of methanol bound to the $\mathrm{Ru}$ center, the PES scan showed that driving the $\mathrm{C}=$ $\mathrm{C}_{\text {dad }}$ backbone to interact with the metal center resulted in spontaneous formation of adduct $\mathbf{A}^{\prime}$. In this complex the methanol is strongly hydrogen bonded to one of the "amido" $\mathrm{N}_{\mathrm{dad}}$ atoms (Figure 2, bottom), while one $\mathrm{C}-\mathrm{H}$ bond of the methyl group weakly interacts with $\mathrm{Ru}$. This fact is highly relevant for catalysis, as it preorganizes the $\mathrm{MeOH}$ molecule for dehydrogenation via a cooperative mechanism, and is illustrative of the large change in electronic structure of both the metal and the ligand from the $\sigma$-bound $(\mathbf{1})$ to $\pi$-bound $\left(\mathbf{1}^{\prime}\right)$ coordination mode of the dad-ligand moiety (also see Figure 1e).

Comparison of charges obtained by natural population analysis (NPA) reveals that the transformation of complex 1 to complex $\mathbf{1}^{\prime}$ results in a net increase of negative charge density on the $\mathrm{N}_{\mathrm{dad}}$ moieties. The metal center becomes more positive during this transformation. These effects are more pronounced in the $\mathrm{MeOH}$ adducts $\mathbf{A}$ and $\mathbf{A}^{\prime}$. For example, in complex $\mathbf{A}^{\prime}$, the $\mathrm{N}_{\mathrm{dad}}$ atom involved in hydrogen bonding to the $\mathrm{MeOH}$ molecule has a 0.10 unit higher net negative natural charge than in complex A. As such, the transformation of a $\sigma$-coordinated dad moiety to a $\pi$-coordinated one significantly changes the electronic structure of the complex. The Brønsted basicity of the nitrogen atoms and the Lewis acidity of the metal ion are 


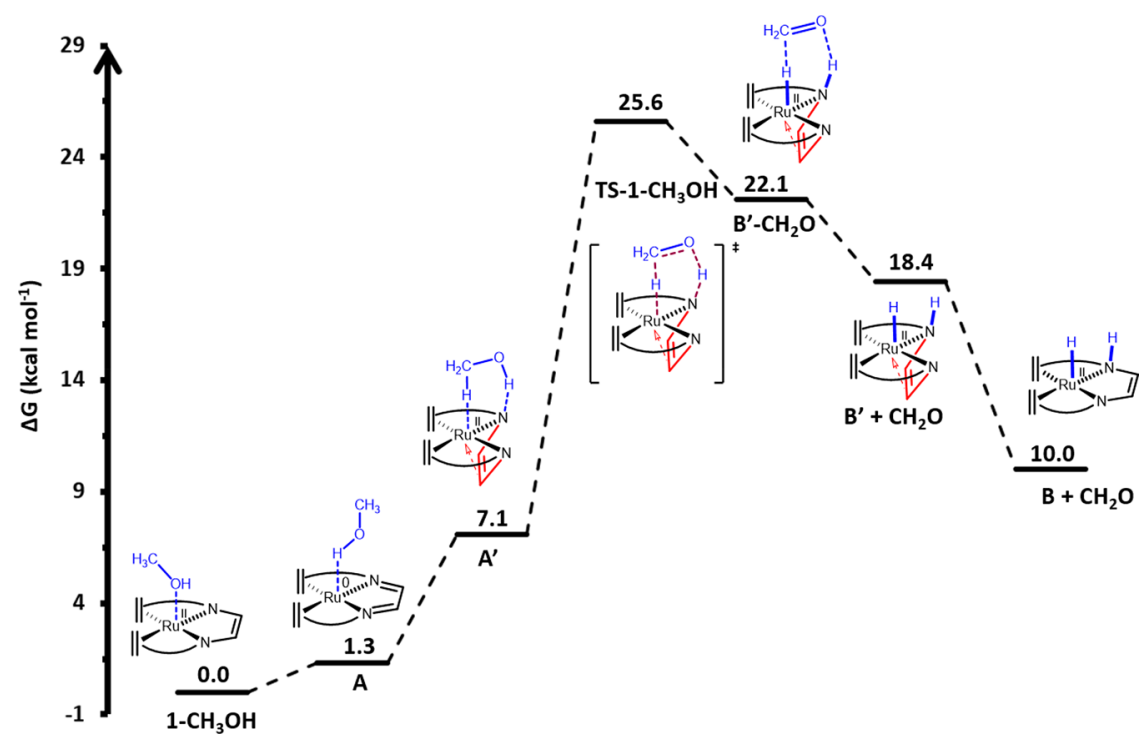

Figure 4. Computed free energy profile for dehydrogenation of methanol to formaldehyde over complex 1 (BP86//B3LYP (Water)). Transient bonds in transition states are drawn as dashed brown lines.

Scheme 3. Direct (Unassisted) and Formic Acid Mediated Pathways for Dehydrogenation of Complex $\mathbf{B}^{a}$

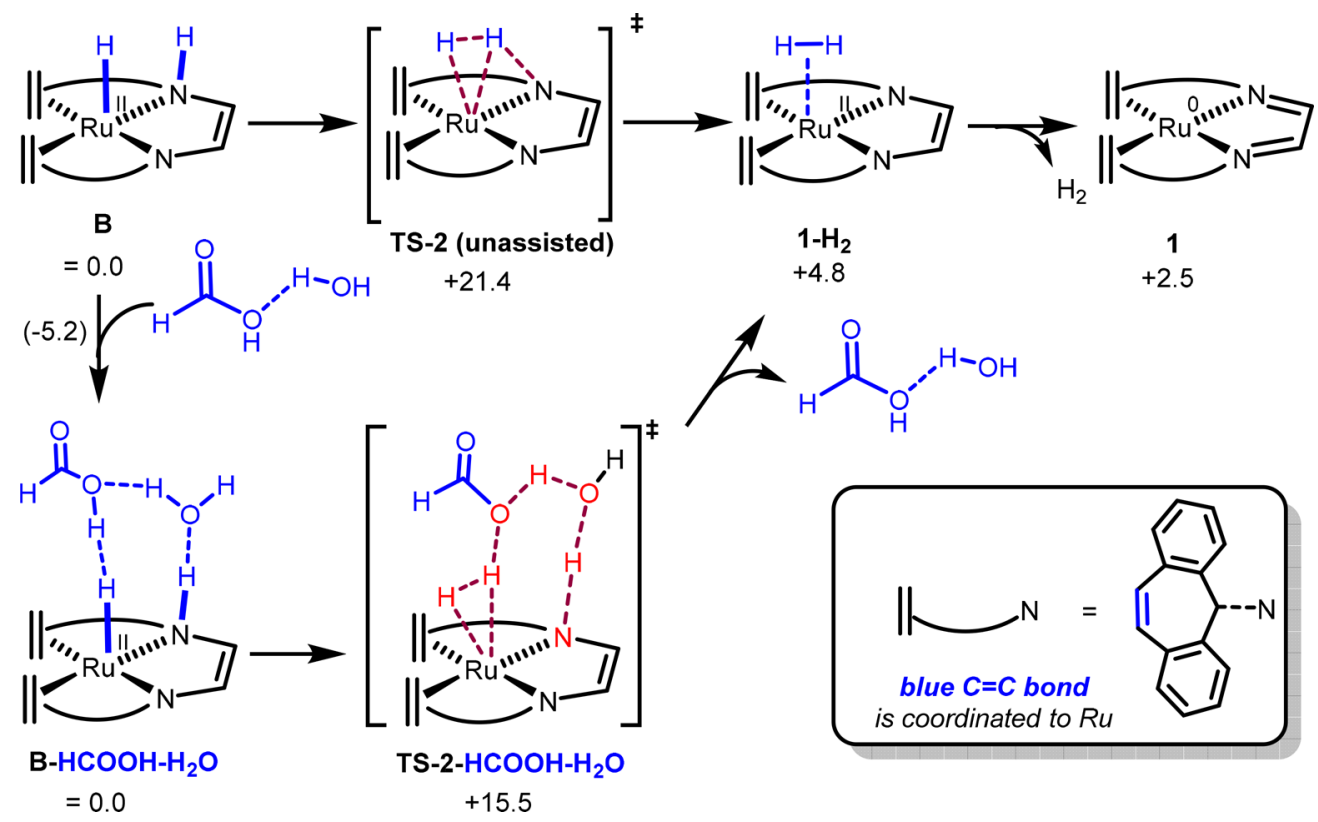

${ }^{a}$ Relative Gibbs free energy $\left(\Delta G^{\circ}{ }_{298 \mathrm{~K}}\right)$ values (BP86//B3LYP (Water)) are reported in kcal mol ${ }^{-1}$ with respect to B-HCOOH- $\mathbf{H}_{2} \mathbf{O}$. The enthalpy $\left(\Delta H^{\circ}{ }_{298} \mathrm{~K}\right)$ for the reaction $\mathrm{B}+\left(\mathrm{HCCOH}-\mathrm{H}_{2} \mathrm{O}\right)$ is given in parentheses. ${ }^{33}$ Transient bonds in transition states are drawn as dashed brown lines.

enhanced. This allows binding of the methanol molecule in a way that dehydrogenation via a cooperative mechanism becomes easily feasible (vide infra).

Simplified Atom Model vs Full-Atom Model. The differences of the relative free energies between the $\kappa$-N-sigma bound and $\pi$-bound forms were studied using a simplified model with cycloheptenyl units instead of the complete trop ${ }_{2}$ dad ligand using various functionals (Figure 3 ). The results clearly show that the simplified atom model systematically overestimates the relative free energy of $\pi$-complex $\mathbf{1}^{\prime}$ relative to $\sigma$-complex $\mathbf{1}$ (Figure 3). This may explain why previous MERPs explored with the simplified atom model did not identify complex $\mathbf{1}^{\prime}$ as a likely intermediate. Further analysis (see Supporting Information) shows that the complexation of methanol over complex 1 and the TS for dehydrogenation of MeOH (TS-1$\mathrm{CH}_{3} \mathrm{OH}$ ) are not described satisfactorily by the simplified atom model either. $\mathrm{Li}$ and Hall showed examples where the simplified atom model underestimates the TS barriers. ${ }^{15}$ Our own calculations show that there are also cases where the simplified model overestimates the TS barriers (see Supporting Information). This comparative study therefore reveals that the use of simplified models of the catalyst leads to unsystematic errors and shows that a full-atom treatment is essential. We therefore performed all further mechanistic studies using only the full-atom models of the catalyst species.

Acceptorless Dehydrogenation of $\mathrm{MeOH}$ to Formaldehyde. The computed pathway for dehydrogenation of methanol to formaldehyde promoted by complex $\mathbf{1}$ is shown in 

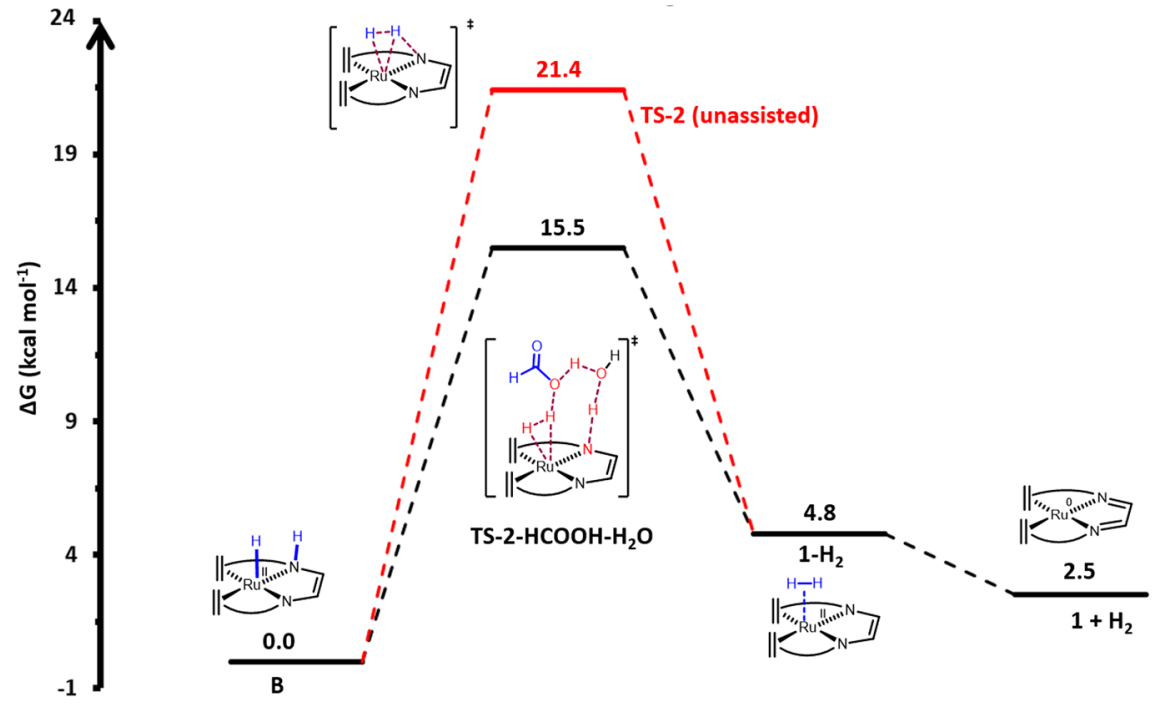

Figure 5. Computed free energy profile for hydrogen production from complex B (BP86//B3LYP (Water)). Transient bonds in transition states are drawn as dashed brown lines.

Scheme 4. Dehydrogenation of Methanediol to Formic Acid ${ }^{a}$

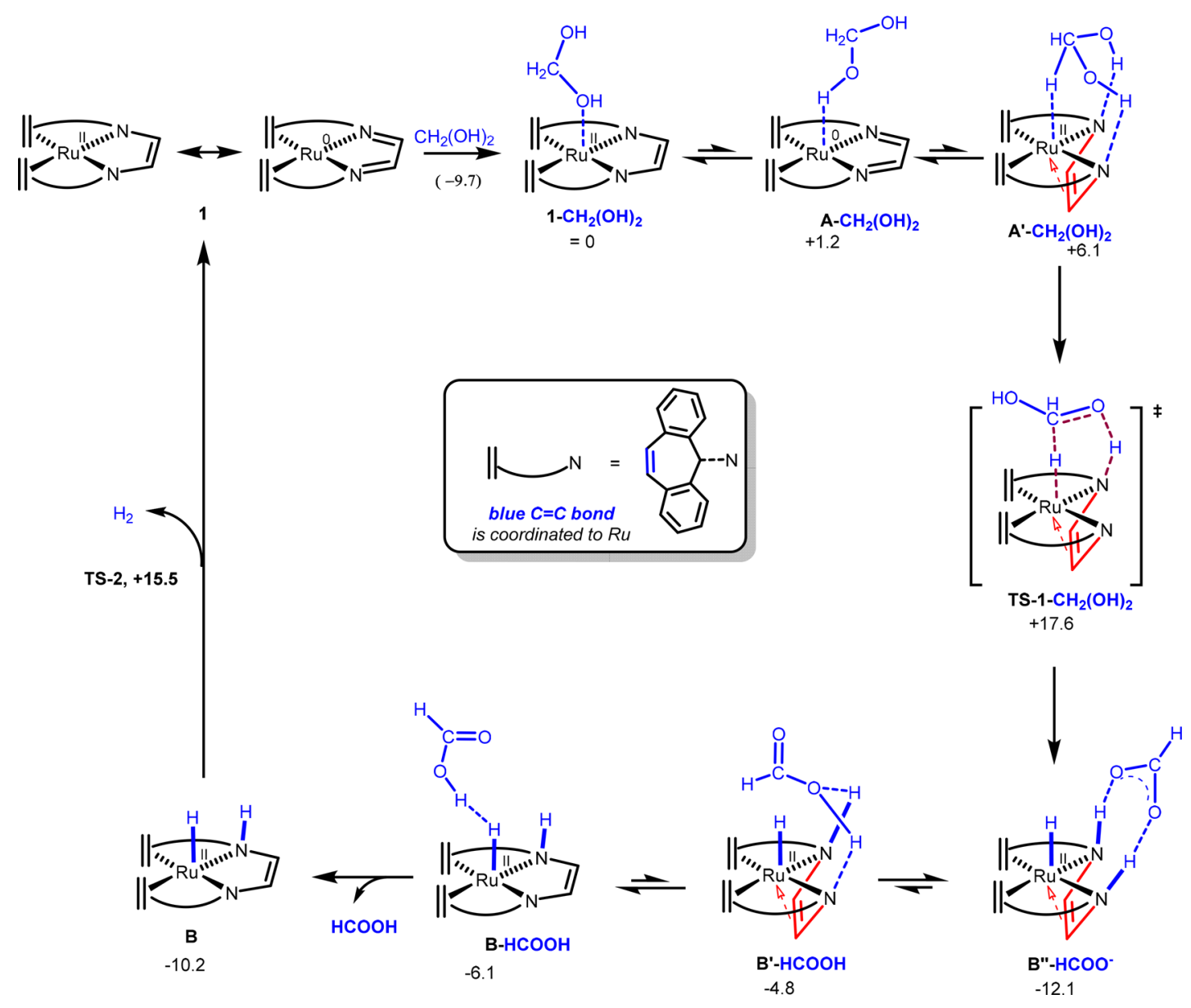

${ }^{a}$ All relative Gibbs free energy $\left(\Delta G^{\circ}{ }_{298 \mathrm{~K}}\right)$ values (BP86//B3LYP (Water)) are reported in kcal mol ${ }^{-1}$ with respect to $1-\mathrm{CH}_{2}(\mathrm{OH})_{2}$. The enthalpy $\left(\Delta H^{\circ}{ }_{298 \mathrm{~K}}\right)$ for the reaction $\mathrm{CH}_{2}(\mathrm{OH})_{2}$ is given in parentheses. ${ }^{33}$ Transient bonds in transition states are drawn as dashed brown lines.

Scheme 2 and Figure 4. In the first exothermic step, methanol binds with its Lewis-basic oxygen center to the Lewis-acidic Ru center of $\mathbf{1}$ to give $\mathbf{1 -} \mathrm{CH}_{3} \mathrm{OH}$. There is another isomer $\mathrm{A}$, only slightly higher in energy $\left(\Delta G^{\circ}{ }_{298 \mathrm{~K}}=+1.2 \mathrm{kcal} \mathrm{mol}^{-1}\right)$, in which the $\mathrm{OH}$ group is hydrogen bonded to the metal center. This is a reflection of the remarkable electronic flexibility of the $\left[\mathrm{Ru}\left(\right.\right.$ trop $\left.\left._{2} \mathrm{dad}\right)\right]$ complex. There is a third possible binding mode of the $\mathrm{CH}_{3} \mathrm{OH}$ ligand that leads to $\mathbf{A}^{\prime}$. In this isomer, the 

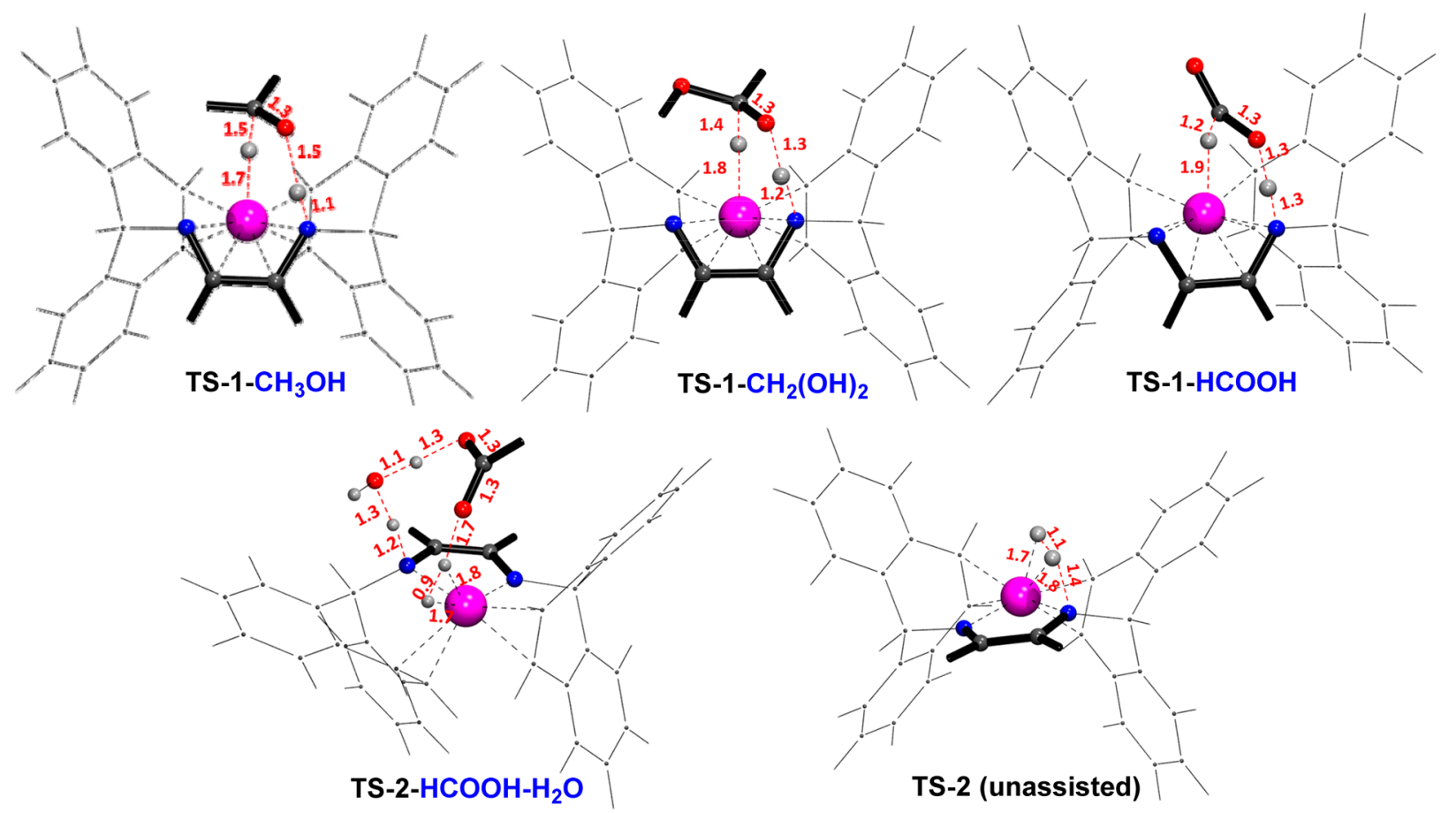

Figure 6. Snapshots of optimized geometries of the transition states reported in the main text along relevant bond lengths (in $\AA$ ).

dad moiety adopts the $\pi$-coordination mode, which renders the $\mathrm{N}$ centers sufficiently basic in order to interact with the protic $\mathrm{OH}$ group, while one $\mathrm{C}-\mathrm{H}$ unit interacts with the metal center $\left(\mathrm{Ru}-\mathrm{H}_{\mathrm{C}}=2.35 \AA\right)$.

The next step is related to the classical Noyori-Morris mechanism $^{36}$ and involves a simultaneous proton transfer from methanol to $\mathrm{N}_{\mathrm{dad}}$ and hydride transfer to the metal center. This reaction proceeds over TS-1- $\mathbf{C H}_{3} \mathrm{OH}$ at $+25.6 \mathrm{kcal} \mathrm{mol}^{-1}$ and gives a weakly hydrogen-bonded $\mathrm{CH}_{2} \mathrm{O}$ complex $B^{\prime}-\mathbf{C H}_{2}$ O. Exergonic loss of formaldehyde from $\mathbf{B}^{\prime}-\mathbf{C H}_{2} \mathbf{O}$ generates the hydrogenated complex $\mathbf{B}^{\prime}$. The $\mathrm{CH}_{2} \mathrm{O}$ released in this step undergoes hydration to methanediol, which is rapidly converted to $\mathrm{CO}_{2}$ and $\mathrm{H}_{2}$ (vide infra). The $\mathrm{C}-\mathrm{C}_{\mathrm{dad}}$ moiety remains $\pi$-coordinated in all steps involving the catalytic conversion of methanol to formaldehyde. The net result is addition of a $\mathrm{H}_{2}$ molecule across the $\mathrm{Ru}-\mathrm{N}$ bond in complex $\mathbf{1}^{\prime}$. The resulting increase in electron density at the metal center makes the $\pi$-complexation unfavorable, facilitating exergonic relaxation of complex $\mathbf{B}^{\prime}$ to form complex $\mathbf{B}$.

Release of Hydrogen from Complex B. Complex B is the hydrogenated form of complex $\mathbf{1}$, and dehydrogenation of complex $\mathbf{B}$ is key to hydrogen production. ${ }^{37}$ The computed pathway for dehydrogenation of complex $\mathbf{B}$ is shown in Scheme 3 and Figure 5. We investigated different possibilities for solvent/ substrate-mediated transition states leading to the dehydrogenated complex 1 (see Supporting Information for details).

The steps leading to hydrogen production proceed via TS-2, producing complex $1-\mathrm{H}_{2}$, containing a labile $\sigma$-bound $\mathrm{H}_{2}$ molecule, ${ }^{38}$ from which $\mathrm{H}_{2}$ is easily released in a weakly exergonic reaction $\left(\Delta G^{\circ}{ }_{298 \mathrm{~K}}=-2.3 \mathrm{kcal} \mathrm{mol}^{-1}\right)$. In the unassisted reaction, TS-2 is at $+21.4 \mathrm{kcal} \mathrm{mol}^{-1} \cdot{ }^{16}$ A significantly lower barrier of $+15.5 \mathrm{kcal} \mathrm{mol}^{-1}$ is obtained when the hydrogen production process is assisted by a formic acid-water complex $\left(\mathrm{HCOOH} \cdots \mathrm{H}_{2} \mathrm{O}\right)$. In the early and late stages of catalysis, production of $\mathrm{H}_{2}$ may be unassisted, but under steady-state conditions, hydrogen production is likely assisted by formic acid.
The overall dehydrogenation process is endergonic with respect to complex $\mathbf{B}$ by $+2.5 \mathrm{kcal} \mathrm{mol}^{-1}$. Under the experimental conditions the process is driven by constant removal of $\mathrm{H}_{2}$ (and $\mathrm{CH}_{2} \mathrm{O}$; vide infra).

Dehydrogenation of Formaldehyde-Water Mixtures to Formic Acid. The computed pathway for dehydrogenation of methanediol (formed by hydration of the formaldehyde released in a previous step ${ }^{6,16}$ ) is shown in Scheme 4.

As computed for the methanol dehydrogenation steps, methanediol can bind to the metal center in three different modes: (1) via its Lewis basic oxygen center (complex 1- $\left.\mathrm{CH}_{2}(\mathrm{OH})_{2}\right)$; (2) via a metal-proton interaction involving one of the $\mathrm{OH}$ groups (complex A- $\mathrm{CH}_{2}(\mathbf{O H})_{2}$ ), and (3) as in the methanediol adduct $\mathrm{A}^{\prime}-\mathrm{CH}_{2}(\mathbf{O H})_{2}$, wherein the dad moiety adopts a $\pi$-coordination mode, rendering the $\mathrm{N}_{\mathrm{dad}}$ atoms sufficiently basic to interact with both protic $\mathrm{OH}$ groups via $\mathrm{H}$-bond interactions and the $\mathrm{Ru}$ center sufficiently Lewis acidic to interact with one of the $\mathrm{C}-\mathrm{H}$ units of the substrate $(\mathrm{Ru}-\mathrm{HC}=$ $2.16 \AA)$. The latter isomer $\left(\mathbf{A}^{\prime}-\mathbf{C H}_{2}(\mathbf{O H})_{2}\right)$ is the entry to product formation. Concerted metal-ligand cooperation allows dehydrogenation of methanediol over the TS-1- $\mathrm{CH}_{2}(\mathrm{OH})_{2}$ at $+17.6 \mathrm{kcal} \mathrm{mol}^{-1}$ to give the hydrogen-bonded formate complex $\mathbf{B}^{\prime \prime}-\mathrm{HCOO}^{-}$in an exergonic reaction $\left(-12.1 \mathrm{kcal} \mathrm{mol}^{-1}\right)$. The whole reaction sequence is thus very similar to the one described above for methanol dehydrogenation over TS-1$\mathrm{CH}_{3} \mathrm{OH}$.

Dissociation of formic acid ( $\mathrm{HCOOH})$ from $\mathbf{B}^{\prime \prime}-\mathbf{H C O O}^{-}$to form the hydrogenated complex $\mathbf{B}$ most likely proceeds via complex $\mathbf{B}^{\prime}-\mathbf{H C O O H}$ (endergonic; $+7.3 \mathrm{kcal} \mathrm{mol}^{-1}$ ), which rearranges to $\mathbf{B}-\mathbf{H C O O H}$ (exergonic; $-1.3 \mathrm{kcal} \mathrm{mol}^{-1}$ ) upon decoordination of the $\mathrm{Ru}$ center from the $\mathrm{C}=\mathrm{C}_{\mathrm{dad}}$ backbone (Scheme 4). From there, the reaction proceeds by dissociation of formic acid $\left(-4.1 \mathrm{kcal} \mathrm{mol}^{-1}\right)$ to form $\mathbf{B}$ and release of $\mathrm{H}_{2}$ $\left(+2.3 \mathrm{kcal} \mathrm{mol}^{-1}\right)$ to regenerate complex $\mathbf{1}$ (vide supra). The reaction from $\mathbf{B}^{\prime \prime}-\mathrm{HCOOH}$ to $\mathbf{1}$ is overall slightly endergonic $\left(+4.2 \mathrm{kcal} \mathrm{mol}^{-1}\right)$, but the process is driven by continuous 
Scheme 5. Dehydrogenation of Formic Acid to Produce $\mathrm{CO}_{2}$ and $\mathrm{H}_{2}$ over $\mathbf{1}^{a}$

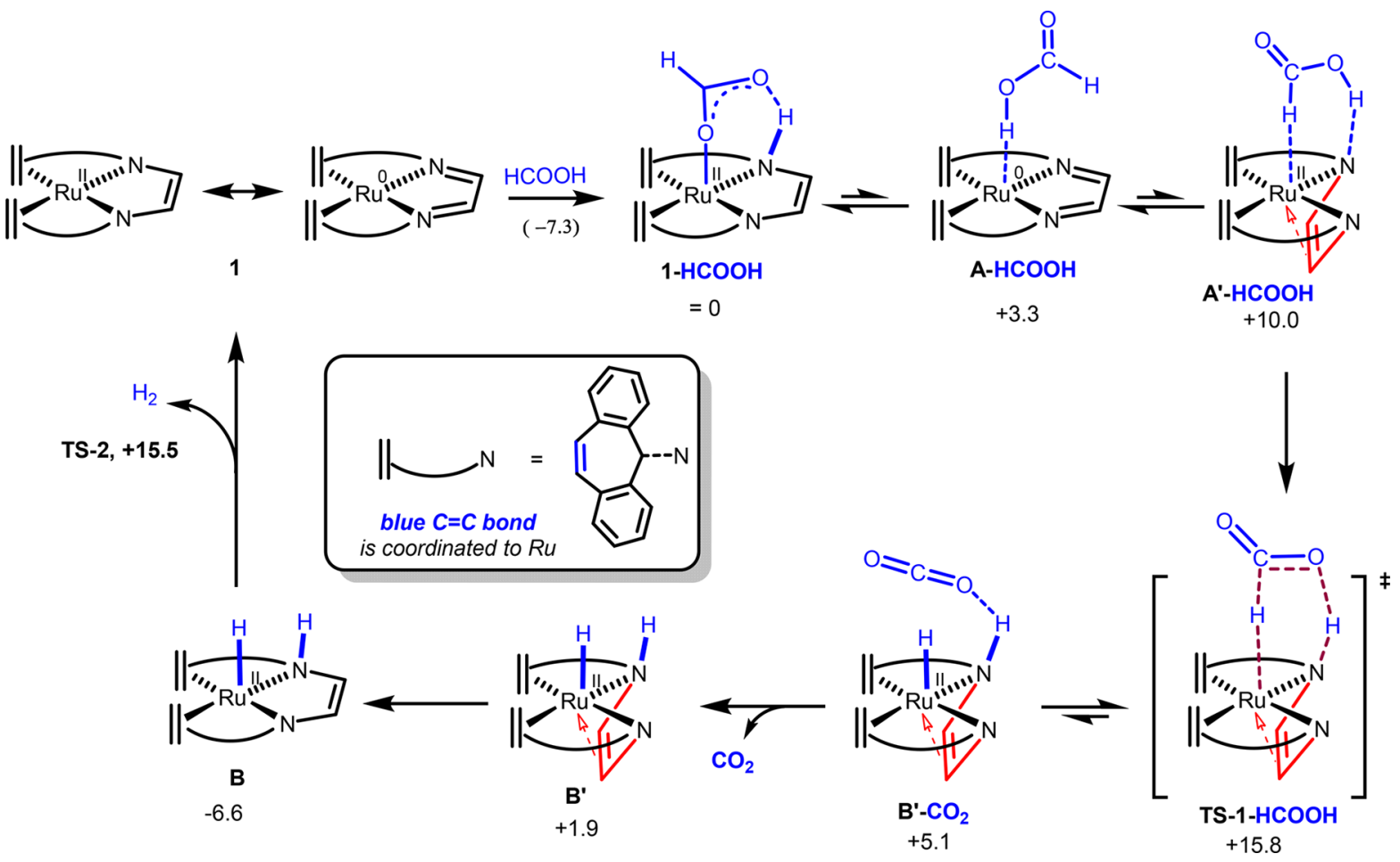

${ }^{a}$ All relative Gibbs free $\left(\Delta G^{\circ}{ }_{298} \mathrm{~K}\right)$ energy values (BP86//B3LYP (Water)) are reported in $\mathrm{kcal} \mathrm{mol}^{-1}$. The number in parentheses is the enthalpy change $\left(\Delta H^{\circ}{ }_{298 \mathrm{~K}}\right)$ of this step. ${ }^{33}$ Transient bonds in transition states are drawn as dashed brown lines.

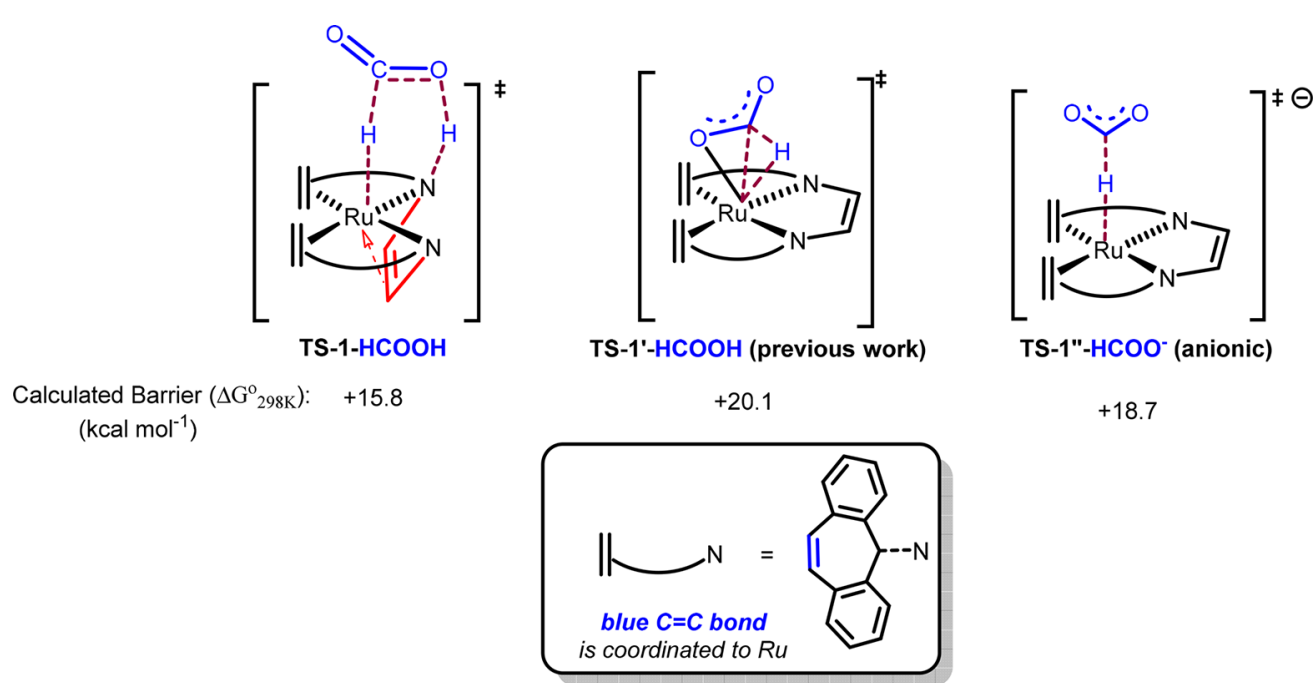

Figure 7. Comparison of transition state for hydride transfer (TS-1-HCOOH) with previous work $^{16}$ and involving an anionic system (BP86// B3LYP (Water)). Transient bonds in the transition states are drawn as dashed brown lines.

removal of gaseous $\mathrm{H}_{2}$ under the experimental conditions. The overall dehydrogenation of methanediol to formic acid is found to be exergonic by $-7.9 \mathrm{kcal} \mathrm{mol}^{-1}$ with respect to complex 1 .

Dehydrogenation of Formic Acid to $\mathrm{CO}_{2}$ over Complex 1. The computed mechanism for the dehydrogenation of formic acid to produce $\mathrm{CO}_{2}$ and $\mathrm{H}_{2}$ is shown in Scheme 5. Dehydrogenation of formic acid over complex 1 proceeds in a similar manner to that of methanol (vide supra). In contrast to methanediol and methanol, protonation of one of the $\mathrm{N}_{\mathrm{dad}}$ moieties by formic acid and subsequent coordination of the formate to the metal center via one of the oxygen atoms to produce complex $1-\mathrm{HCOOH}$ is exergonic.
This species is the resting state of the catalytic cycle for dehydrogenation of formic acid. Complex 1-HCOOH undergoes an endergonic rearrangement to form $\mathrm{A}-\mathrm{HCOOH}$, where formic acid interacts with the metal center via a metal-proton interaction, analogous to complex A. Coordination of the $\mathrm{C}=$ $\mathrm{C}_{\text {dad }}$ backbone to the metal center generates the $\pi$-coordinated complex $\mathbf{A}^{\prime}$-HCOOH. Complexes A-HCOOH and $\mathbf{A}^{\prime}-\mathbf{H C O O H}$ should exist in equilibrium with each other. In a similar manner to that computed for the dehydrogenation of methanol via TS-1- $\mathrm{CH}_{3} \mathrm{OH}$ and dehydrogenation of methanediol via TS-1$\mathrm{CH}_{2}(\mathrm{OH})_{2}$, a concerted Noyori-Morris-type mechanism via transition state TS-1-HCOOH at $+15.8 \mathrm{kcal} \mathrm{mol}^{-1}$ leads to the 
formation of the $\mathrm{CO}_{2}$ adduct $\mathbf{B}^{\prime}-\mathbf{C O}_{2}$. Exergonic loss of $\mathrm{CO}_{2}$ from $\mathbf{B}^{\prime}-\mathbf{C O}_{2}$ generates the complex $\mathbf{B}^{\prime}$, which rearranges in an exergonic process to complex $\mathbf{B}$. As discussed above, this complex finally loses $\mathrm{H}_{2}$ to regenerate complex $\mathbf{1}$ (vide supra), thus completing the catalytic cycle. The overall dehydrogenation of formic acid to $\mathrm{CO}_{2}$ and $\mathrm{H}_{2}$ is found to be exergonic by $-7.5 \mathrm{kcal} \mathrm{mol}^{-1}$.

Quantifying the Effect of Metal-Ligand Cooperativity. Dehydrogenation of formic acid by complex 1 provides an exemplary case to quantify the effect of metal-ligand cooperativity arising from the transformation of a $\sigma$-bound (complex $\mathbf{1}$ ) to a $\pi$-bound (complex $\mathbf{1}^{\prime}$ ) dad moiety. The experimental turnover frequency (TOF) for formic acid dehydrogenation over complex $\mathbf{1}$ is one of the highest reported $\left(24000 \mathrm{~h}^{-1}\right)$, indicating a relatively low barrier for oxidation of formic acid to $\mathrm{CO}_{2}$ promoted by complexes $1 / \mathbf{1}^{\prime}$. In our earlier work, we calculated the dehydrogenation of formic acid by complex $\mathbf{1}$ in the absence of $\pi$-coordination of the $\mathrm{Ru}$ center with the $\mathrm{C}=\mathrm{C}_{\mathrm{dad}}$ backbone. ${ }^{16}$ In addition, Yang and co-workers have reported an anionic TS for hydride transfer from formate to complex 1 to produce $\mathrm{CO}_{2}$ and $\mathbf{1} \mathbf{H}^{-}$using a simplified atom model. ${ }^{17}$ We recomputed this cycle using a full-atom model of complex 1. Figure 7 summarizes these findings. Within the manifold of calculated reactions, formic acid dehydrogenation via TS-1-HCOOH proceeds with the lowest barrier of $+15.8 \mathrm{kcal} \mathrm{mol}^{-1}$. All of the transition states considered in Figure 7 involve a hydride transfer from an anionic formate moiety to the metal center. To reach an energetically favorable TS for the dehydrogenation of formic acid/formate, the Ru center should be highly Lewis acidic in order to be a strong hydride acceptor. Furthermore, little steric hindrance in the TS geometry and a favorable stabilization of the formate moiety by hydrogen bond interactions will lower the activation barrier. TS-1'-HCOOH involves a classical beta-hydride transfer from an O-coordinated formate to $\mathrm{Ru}$. Not only does the molecular geometry of TS-1'-HCOOH suffer from steric hindrance, it also lacks hydrogen bond stabilization of the formate moiety in the TS. Moreover, there is no particular enhancement in the Lewis acidity of the metal center. It is therefore a little surprising that TS-1'-HCOOH has the highest energy $\left(+20.1 \mathrm{kcal} \mathrm{mol}^{-1}\right)$ among the activated complexes shown in Figure 5. The anionic TS-1" $\mathbf{1}^{\prime \prime}-\mathrm{HCOO}^{-}$is sterically less hindered compared to TS-1'$\mathbf{H C O O H}$, thus leading to a somewhat lower barrier of $+18.7 \mathrm{kcal} \mathrm{mol}^{-1}$. However, it should be noted that in the absence of any $\mathrm{H}$-bond stabilization of the formate anion by explicit solvent molecules, the computed energy of the activated complex TS-1" $\mathbf{H C O O}^{-}$is actually unrealistic and most likely considerably underestimated. ${ }^{39}$ The geometry of the neutral transition state TS-1-HCOOH features a sterically favored arrangement of catalyst and substrate in a six-membered ring, a stabilization of the formate moiety by hydrogen bonds, and a $\pi$-bound dad ligand, which increases the Lewis acidity of the $\mathrm{Ru}^{\mathrm{II}}$ center. The combination of these factors leads to a relatively low barrier for $\mathrm{CO}_{2}$ production. ${ }^{34}$ The calculated barrier of $+15.8 \mathrm{kcal} \mathrm{mol}^{-1}$ is consistent with the experimentally observed high TOF values for formic acid dehydrogenation promoted by complex $\mathbf{1}$. Similar arguments can be used to rationalize the relatively low barriers for dehydrogenation of methanol and methanediol (see the Supporting Information).

\section{SUMMARY AND CONCLUSIONS}

In summary, the mechanism for complete dehydrogenation of aqueous methanol to $\mathrm{CO}_{2}$ and three equivalents of $\mathrm{H}_{2}$ cata- lyzed by $\left[\mathrm{Ru}\left(\right.\right.$ trop $\left.\left._{2} \mathrm{dad}\right)\right]$ was investigated with DFT employing the full-atom model of the catalyst. Previous computational mechanistic studies on this system using a simplified model of the catalyst proposed a fully ligand centered anionic pathway, with the metal acting as merely a spectator. This pathway requires crossing of high TS barriers for dehydrogenation of aqueous methanol, inconsistent with the experimental results. In this study we show that the dad ligand moiety plays an active role as a cooperative ligand with the metal in the dehydrogenation mechanism, leading to much lower TS barriers. We find that the dad moiety rearranges from a $\sigma$-bound to a $\pi$-bound coordination mode, resulting in an enhanced Brønsted basicity of the amido nitrogen atoms and a stronger Lewis acidity of the metal center. This crucial rearrangement allows a favorable coordination of the substrate to the $\mathrm{Ru}$ center to open effective catalytic reaction channels for substrate dehydrogenation. The geometric and electronic fluxionality of the dad ligand moiety gives access to metal-ligand cooperativity, providing pathways with low activation barriers for alcohol activation and $\mathrm{H}_{2}$ production in an aqueous medium. Overall, dehydrogenation of the substrate (methanol/methanediol/formic acid) occurs via a Noyori-Morris-type mechanism to form complex $[\mathrm{Ru}(H)$ (tropN $H-\mathrm{CH}=\mathrm{CH}-\mathrm{Ntrop})]$ B, which is a hydrogenated form of complex 1 . Subsequent dehydrogenation of complex $\mathbf{B}$ can occur directly or via substrate/solvent-assisted pathways, both having relatively low activation barriers. The cooperative function of $\pi$-bound dad ligand moieties might well be a more general feature of catalysts with diazadiene ligands, and it could therefore be key for the design of improved catalysts for hydrogen production from methanol-water mixtures.

\section{ASSOCIATED CONTENT}

S Supporting Information

The Supporting Information is available free of charge on the ACS Publications website at DOI: 10.1021/jacs.8b09011.

Additional computational data, other possible reaction pathways, xyz coordinates, and benchmark calculations (PDF)

\section{AUTHOR INFORMATION}

\section{Corresponding Authors}

*hgruetzmacher@ethz.ch

*b.debruin@uva.nl

ORCID $\odot$

Vivek Sinha: 0000-0002-6856-9469

Bas de Bruin: 0000-0002-3482-7669

\section{Notes}

The authors declare no competing financial interest.

\section{ACKNOWLEDGMENTS}

This work was supported by the Schweizer Nationalfonds (SNF 200021_162437/1), Eidgenössische Technische Hochschule $(\mathrm{ETH})$ Zürich, The Netherlands Organization for Scientific Research NWO-CW (VICI project 016.122.613), the NWO-Shell Computational Sciences for Energy Research Initiative (project 13CSER003), and the RPA Sustainable Chemistry of the University of Amsterdam (UvA). The calculations were carried out on the Dutch national e-infrastructure with the support of the SURF cooperative. 


\section{REFERENCES}

(1) Olah, G. A.; Goeppert, A.; Prakash, G. K. S. Beyond Oil and Gas: The Methanol Economy, $2^{\text {nd }}$ ed.; Wiley: Weinheim, 2009.

(2) Goeppert, A.; Czaun, M.; Jones, J. P.; Prakash, G. K. S.; Olah, G. A. Recycling of carbon dioxide to methanol and derived products closing the loop. Chem. Soc. Rev. 2014, 43, 7995-8048.

(3) Palo, D. R.; Dagle, R. A.; Holladay, J. D. Methanol steam reforming for hydrogen production. Chem. Rev. 2007, 107, 39924021.

(4) Morton, D.; Cole-Hamilton, D. J. Rapid thermal hydrogen production from alcohols catalysed by $\left[\mathrm{Rh}\left(2,2^{\prime} \text {-bipyridyl }\right)_{2}\right] \mathrm{Cl}$. $J$. Chem. Soc., Chem. Commun. 1987, 0, 248-249.

(5) Nielsen, M.; Alberico, E.; Baumann, W.; Drexler, H. J.; Junge, H.; Gladiali, S.; Beller, M. Low-temperature aqueous-phase methanol dehydrogenation to hydrogen and carbon dioxide. Nature 2013, 495, 85-89.

(6) Rodríguez-Lugo, R. E.; Trincado, M.; Vogt, M.; Tewes, F.; Santiso-Quinones, G.; Grützmacher, H. A homogeneous transition metal complex for clean hydrogen production from methanol-water mixtures. Nat. Chem. 2013, 5, 342-347.

(7) (a) Hu, P.; Diskin-Posner, Y.; Ben-David, Y.; Milstein, D. Reusable homogeneous catalytic system for hydrogen production from methanol and water. ACS Catal. 2014, 4, 2649-2652. (b) Van de Watering, F. F.; Lutz, M.; Dzik, W.; de Bruin, B.; Reek, J. Reactivity of a ruthenium-carbonyl complex in the methanol dehydrogenation reaction. Chem CatChem 2016, 8, 2752-2756.

(8) Monney, A.; Barsch, E.; Sponholz, P.; Junge, H.; Ludwig, R.; Beller, M. Base-free hydrogen generation from methanol using a bicatalytic system. Chem. Commun. 2014, 50, 707-709.

(9) (a) Linn, D. E., Jr.; Halpern, J. Roles of neutral and anionic ruthenium polyhydrides in the catalytic hydrogenation of ketones and arenes. J. Am. Chem. Soc. 1987, 109, 2969-2974. (b) Fujita, K.; Kawahara, R.; Aikawa, T.; Yamaguchi, R. Hydrogen production from a methanol-water solution catalyzed by an anionic iridium complex bearing a functional bipyridonate ligand under weakly basic conditions. Angew. Chem., Int. Ed. 2015, 54, 9057-9060. (c) Prichatz, C.; Alberico, E.; Baumann, W.; Junge, H.; Beller M, M. Iridium-PNP pincer complexes for methanol dehydrogenation at low base concentration. ChemCatChem 2017, 9, 1891-1896.

(10) Zhan, Y. L.; Shen, Y. B.; Li, S. P.; Yue, B. H.; Zhou, X. C. Hydrogen generation from methanol reforming under unprecedented mild conditions. Chin. Chem. Lett. 2017, 28, 1353-1357.

(11) (a) Alberico, E.; Sponholz, P.; Cordes, C.; Nielsen, M.; Drexler, H. J.; Baumann, W.; Junge, H.; Beller, M. Selective hydrogen production from methanol with a defined iron pincer catalyst under mild conditions. Angew. Chem., Int. Ed. 2013, 52, 14162-14166. (b) Bielinski, E. A.; Förster, M.; Zhang, Y.; Bernskoetter, W. H.; Hazari, N.; Holthausen, M. C. Base-free methanol dehydrogenation using a pincer-supported iron compound and Lewis acid co-catalyst. ACS Catal. 2015, 5, 2404-2415.

(12) Andérez-Fernández, M.; Vogt, L. K.; Fischer, S.; Zhou, W.; Jiao, H.; Garbe, M.; Elangovan, S.; Junge, K.; Junge, H.; Ludwig, R.; Beller, M. A stable manganese pincer catalyst for the selective dehydrogenation of methanol. Angew. Chem., Int. Ed. 2017, 56, 559-562.

(13) Sinha, V.; Pribanic, B.; de Bruin, B.; Trincado, M.; Grützmacher, H. Ligand- and Metal-Based Reactivity of a Neutral Ruthenium Diolefin Diazadiene Complex: The Innocent, the Guilty and the Suspicious. Chem. - Eur. J. 2018, 24, 5513-5521.

(14) Li, H.; Hall, M. B. Role of the Chemically Non-Innocent Ligand in the Catalytic Formation of Hydrogen and Carbon Dioxide from Methanol and Water with the Metal as the Spectator. J. Am. Chem. Soc. 2015, 137, 12330-12342.

(15) (a) Despite the wealth of coordination compounds containing $\mathrm{Ru}^{\mathrm{II}}$, anionic complexes are not common, and when accessible, they carry $\pi$-acceptor ligands. See for example: Wu, F.; Wang, C. J.; Lin, H.; Hui, A. Q.; Jia, A.; Zhang, Q. Syntheses, structures and catalytic properties of ruthenium(II) nitrosyl complexes with bidentate and tetradentate Schiff base ligands. Inorg. Chim. Acta 2018, 471, 718723. (b) Anionic complexes are rarely used for (or even observed to be active in) catalytic hydrogen transfer or dehydrogenation processes. See also ref 9 a.

(16) Trincado, M.; Sinha, V.; Rodriguez-Lugo, R. E.; Pribanic, B.; de Bruin, B.; Grützmacher, H. Homogeneously catalysed conversion of aqueous formaldehyde to $\mathrm{H}_{2}$ and carbonate. Nat. Commun. 2017, 8, 14990.

(17) Jing, Y.; Chen, X.; Yang, X. Theoretical study of the mechanism of ruthenium catalyzed dehydrogenation of methanol-water mixture to $\mathrm{H}_{2}$ and $\mathrm{CO}_{2}$. J. Organomet. Chem. 2016, 820 (C), 55-61.

(18) $\mathrm{Li}$ and Hall calculated proton abstraction from complex 2 to generate $2^{-}$to be uphill by $8.6 \mathrm{kcal} \mathrm{mol}^{-1}$ in aqueous media, meaning that $\mathbf{2}$ must be considered as the resting state for dehydrogenation of $2^{-}$to regenerate complex $1 \mathbf{H}^{-}$. Yang computed the deprotonation of complex 2 to generate $2^{-}$to be uphill by $3.4 \mathrm{kcal} \mathrm{mol}^{-1}$.

(19) University of Karlsruhe and Forschungszentrum Karlsruhe GmbH. TURBOMOLE V7.1; TURBOMOLE GmbH, 2016.

(20) Baker, J. An algorithm for the location of transition states. J. Comput. Chem. 1986, 7, 385-395.

(21) Budzelaar, P. H. M. Geometry optimization using generalized, chemically meaningful constraints. J. Comput. Chem. 2007, 28, 22262236.

(22) Perdew, J. P. Density-functional approximation for the correlation energy of the inhomogeneous electron gas. Phys. Rev. B: Condens. Matter Mater. Phys. 1986, 33, 8822-8824.

(23) Becke, A. D. Density-functional exchange-energy approximation with correct asymptotic behavior. Phys. Rev. A: At., Mol., Opt. Phys. 1988, 38, 3098-3100.

(24) Weigend, F.; Ahlrichs, R. Balanced basis sets of split valence, triple zeta valence and quadruple zeta valence quality for $\mathrm{H}$ to $\mathrm{Rn}$ : Design and assessment of accuracy. Phys. Chem. Chem. Phys. 2005, 7, 3297-3305.

(25) Eichkorn, K.; Weigend, F.; Treutler, O.; Ahlrichs, R. Auxiliary basis sets for main row atoms and transition metals and their use to approximate Coulomb potentials. Theor. Chem. Acc. 1997, 97, 119124

(26) Eichkorn, K.; Treutler, O.; Öhm, H.; Häser, M.; Ahlrichs, R. Auxiliary basis sets to approximate Coulomb potentials. Chem. Phys. Lett. 1995, 240, 283-290.

(27) Weigend, F. Accurate Coulomb-fitting basis sets for H to Rn. Phys. Chem. Chem. Phys. 2006, 8, 1057-1065.

(28) Grimme, S.; Antony, J.; Ehrlich, S.; Krieg, H. A consistent and accurate $\mathrm{ab}$ initio parametrization of density functional dispersion correction (DFT-D) for the 94 elements H-Pu,. J. Chem. Phys. 2010, 132, 154104.

(29) Klamt, A.; Schüürmann, G. COSMO: a new approach to dielectric screening in solvents with explicit expressions for the screening energy and its gradient. J. Chem. Soc., Perkin Trans. 2 1993, 799-805.

(30) In our previous work (ref 13) we found that one of the possible valence isomers of complex $\mathbf{1}$ can be described as $\mathrm{Ru}^{\mathrm{I}}$ coordinated to a monoanionic dad radical, with spin densities on the metal and ligand center being antiparallel to each other. Detailed calculations showed that this singlet-biradical character does not influence the catalytic reaction pathway for dehydrogenation of a methanol-water mixture. Detailed analysis is presented in the Supporting Information (this paper). For the sake of simplicity, we have not involved this singletbiradical character in the discussion here.

(31) We also considered $C_{d a d}$ as internal base, but the resulting TS barriers for the formation of formaldehyde were found to be relatively high $\left(>30 \mathrm{kcal} \mathrm{mol}^{-1}\right)$. Further details are presented in the Supporting Information.

(32) (a) Vrieze, K. Advances in the chemistry of heterodiene metal complexes. J. Organomet. Chem. 1986, 300, 307-326. For some related $\pi$-coordinated complexes, see: (b) Van Koten, G.; Vrieze, K. 1,4-Diaza-1,3-butadiene ( $\alpha$-Diimine) Ligands: Their Coordination Modes and the Reactivity of Their Metal Complexes. Adv. Organomet. Chem. 1982, 21, 151-239. (c) Dzik, W. I.; Calvo, S. E.; Reek, J. N. H.; Lutz, M.; Ciriano, M. A.; Tejel, C.; Hetterscheid, D. G. H.; de Bruin, B. Binuclear $[(\mathrm{cod})(\mathrm{Cl}) \operatorname{Ir}(\mathrm{bpi}) \operatorname{Ir}(\mathrm{cod})]^{+}$for Catalytic Water 
Oxidation. Organometallics 2011, 30, 372-374. (d) Tejel, C.; Ciriano, M. A.; del Río, M. P.; van den Bruele, F. J.; Hetterscheid, D. G. H.; Tsichlis i Spithas, N.; de Bruin, B. Deprotonation induced ligand-tometal electron transfer: Synthesis of a mixed-valence $\mathrm{Rh}(-\mathrm{I}, \mathrm{I})$ dinuclear compound and its reaction with dioxygen. J. Am. Chem. Soc. 2008, 130, 5844-5845.

(33) The substrate methanol is also the solvent in the system. Therefore, the translational entropy contribution to the methanol binding step should be virtually zero, making enthalpy a better estimate for the free energy of this step in solution than the gas phase free energy based on vibrational analyses only.

(34) Note that introducing explicitly solvent interactions has only a minor influence on the MERP pathways and relative free energies of the minima and transition states (see Supporting Information). The trop ligands in complex $\mathbf{1}$ form a relatively hydrophobic pocket around the metal center, which explains the minimal effects of introducing explicit solvent molecules on the computed MERP of complex $\mathbf{1}$.

(35) We also computed the pathways for methanol dehydrogenation to formaldehyde by $\left[\mathrm{Ru}\left(\right.\right.$ trop $_{2}$ dae) $]$ complex 2 (derived from complex 1 by hydrogenation of the dad backbone). See Supporting Information for details.

(36) For a selection of reviews, see: (a) Noyori, R.; Ohkuma, T. Asymmetric catalysis by architectural and functional molecular engineering: Practical chemo- and stereoselective hydrogenation of ketones. Angew. Chem., Int. Ed. 2001, 40, 40-73. (b) Clapham, S. E.; Hadzovic, A.; Morris, R. H. Mechanisms of the $\mathrm{H}_{2}$-hydrogenation and transfer hydrogenation of polar bonds catalyzed by ruthenium hydride complexes. Coord. Chem. Rev. 2004, 248, 2201-2237. (c) Muñiz, K. Bifunctional metal-ligand catalysis: Hydrogenations and new reactions within the metal-(di)amine scaffold. Angew. Chem., Int. Ed. 2005, 44, 6622-6627.

(37) The direct hydrogen production from complex $\mathbf{B}^{\prime}$ was found to occur via a high TS barrier process $\left(\sim 40 \mathrm{kcal} \mathrm{mol}^{-1}, \mathrm{BP} 86 / \mathrm{def2}-\right.$ TZVP) and was not investigated further.

(38) The mechanistic step forming a nonclassical dihydrogen complex which leads to the regeneration of the catalyst is commonly proposed in dehydrogenation (or the microscopically reverse hydrogenation) reactions. See, for example: Jessop, P. J.; Morris, R. $\mathrm{H}$. Reactions of transition metal dihydrogen complexes. Coord. Chem. Rev. 1992, 121, 155-284.

(39) Sinha, V.; Govindarajan, N.; de Bruin, B.; Meijer, E. J. How Solvent Affects C-H Activation and Hydrogen Production Pathways in Homogeneous Ru-Catalysed Methanol Dehydrogenation Reactions. ACS Catal. 2018, 8, 6908-6913. 